\title{
Opioid prescriptions still rising but for smaller quantities
}

- Cite as: CMAJ 2017 December 11;189:E1538. doi: 10.1503/cmaj.109-5533

Posted on cmajnews.com on Nov. 22, 2017.

anadian doctors are prescribing smaller quantities of opioids, but the number of prescriptions has increased in the past five years, as has the share of strong opioids prescribed, according to new data from the Canadian Institute for Health Information (CIHI).

Between 2012 and 2016, the quantity of opioids dispensed in Canada decreased $4.6 \%$ to 226 million defined daily doses, a measure based on the average daily maintenance dose per prescription for adults. Over the same period, the number of opioid prescriptions increased $6.8 \%$ to 21.5 million last year.

"It's a bit of a mixed result," says Michael Gaucher, director of Pharmaceuticals and Health Workforce Information Services at $\mathrm{CIHI}$. It may be that doctors are prescribing smaller amounts for shorter periods, and reassessing patients for new prescriptions, he explains. Even though prescriptions are going up, "that may not be a bad thing if they're being reviewed more often and stopped when they're not needed."

Most of the decline in the quantity of opioids prescribed happened in the past year, suggesting doctors may be shifting their prescribing habits in response to the worsening overdose crisis, he adds.

However, "the fact that such a large number of people are still being prescribed opioids continues to be a concern."

Doctors are also prescribing strong opioids more often. These higher potency drugs, such as oxycodone and morphine, accounted for $57.3 \%$ of opioid prescriptions in 2016, up from 52.2\% in 2012.

This may reflect "fewer lower potency opioids being prescribed," as doctors restrict their use of the painkillers to the treatment of severe pain, Gaucher explains. "It's difficult to know for sure because we can't examine appropriateness."

He also questions the appropriateness of high rates of prescribing to seniors, and Newfoundland and Labrador had the highest, at 7955 and 7878.

These differences can't be explained by "patient demographics and formulary coverage," says Gaucher. "It seems to

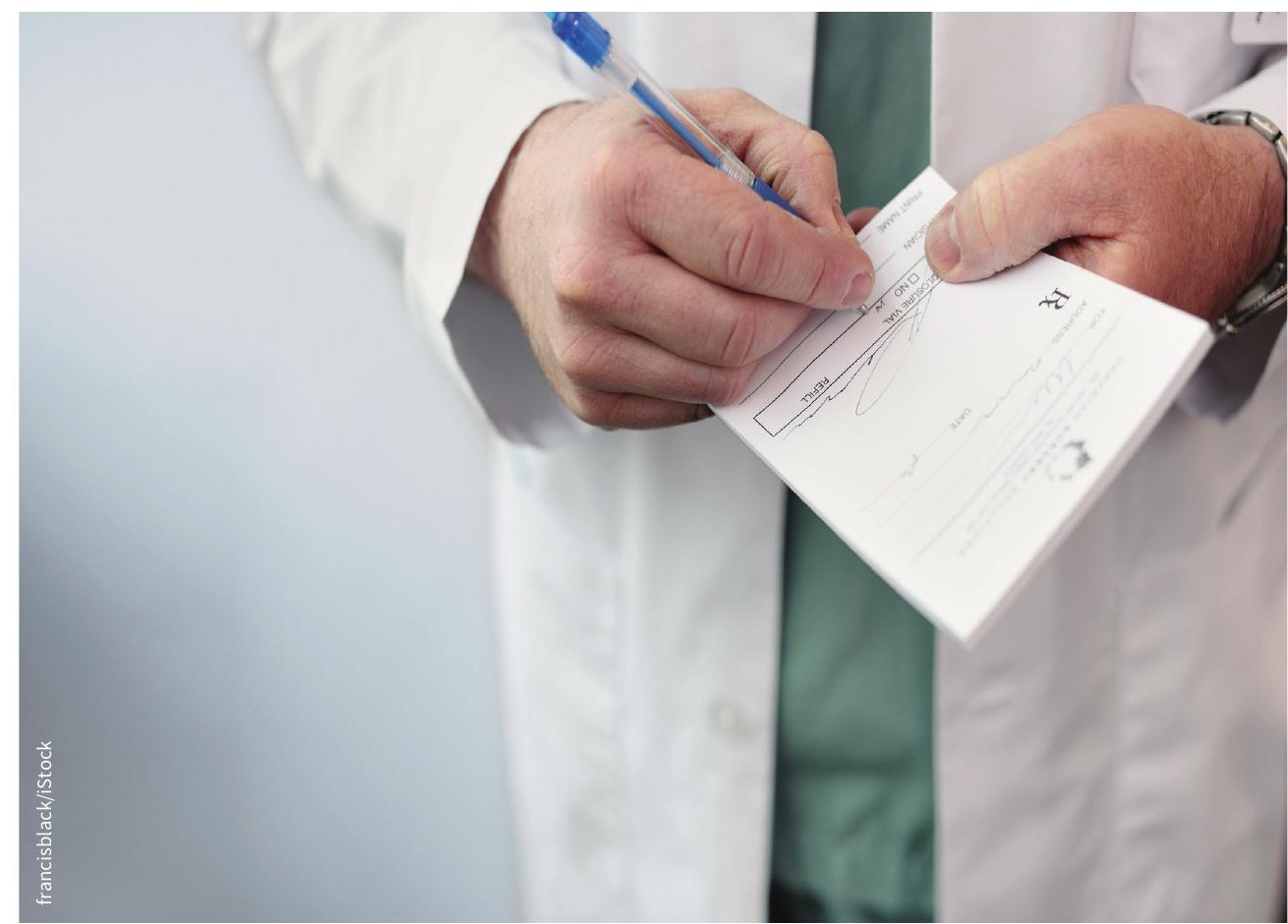

Between 2012 and 2016, the quantity of opioids dispensed in Canada decreased 4.6\%, the Canadian Institute for Health Information reports.

who face the greatest risk of harm from opioids. One in five seniors had at least one opioid prescription in 2015-2016, and one in eight took a strong opioid on a regular basis.

Prescribing practices differed across the provinces, too. British Columbia and Quebec had the lowest number of opioid doses dispensed per 1000 people in 2016, at 5496 and 3601, respectively. Alberta come back to different approaches to managing pain."

He notes that $\mathrm{BC}$ was an early adopter of American guidelines that warned doctors to avoid prescribing high-dose opioids for chronic pain. "But also just the awareness of the crisis there is influencing what we're seeing and driving trends."

Lauren Vogel, CMAJ 